Superstars power, mining the paths to stars' persuasion

\title{
Ana Suárez-Vázquez, Elena Montañés-Roces
}

\begin{abstract}
This paper analyzes the influence of star power on the cinema market. The study adopts two gauges of star power, one based on the industry's opinion and one based on the market's interest. The article merges contributions in the persuasion and cinema market literatures to examine the influence of star power over spectators. This study use machine learning methods based on support vector ordinal regression to analyze the paths to superstars' persuasion. The present research shows differences in the persuasion effect of star power based on the industry and star power based on the market. Similarly, there are differences in the influence of star power among men and women. The results of this study help to explain the mixed findings of previous research on superstars' power.
\end{abstract}

Keywords: movie industry; star power; persuasion; machine learning; support vector ordinal regression

\section{Introduction}

Research on the influence of superstars on box office revenue has yielded somewhat mixed results. The lack of unanimity in the interpretation of the relationship between stars and success has been attributed to four different reasons: (1) the problem that studies address; (2) the data collection approach; (3) the estimation procedures; (4) the concept of "superstar". In the context of movie stars worth, these dimensions typically take the following form: (1) 
the studies analyzes the relationship between the presence of superstars and the box office revenue; (2) data collection involves using some of the cinema bases available; (3) standard ordinary least square approaches dominate cinema revenues' modeling; (4) studies apply a specific measure of star power.

Traditionally, star power literature has focused on answering whether the presence of superstars increase cinema revenues or returns to investment (Ravid 1999). A complementary approach is to address the mechanism by what the presence of a superstar can increase spectators' interest in a given film. The degree to which a person is motivated to thoughtfully consider the merits of a particular object has received a great deal of attention in marketing literature. The attitude and behavior change resulting from the power of persons is known as persuasion (Cacioppo, Petty and Berntson 1991). This idea suggests the possibility of improving the knowledge about star power applying current work of persuasion.

In comparison with the majority of the sectors, the cinema industry has the privilege of the availability of enormous and rich data bases (e.g. www.imdb.com, www.boxofficemojo.com). Instead of studying collective movie attendance decisions, gathering the information of individual spectators can provide a psychological explanation about why individuals choose particular movies (Eliashberg et al. 2007).

In the past few years, remarkable progress in cinema revenues' distribution modeling have been possible due to the application of non-standard models to modeling motion-picture profit (Walls 2009). In environments in which there are complex relationships between predictor and target variables support vector machine (SVM) suits well. The SVM is a semiparametric technique with origins in the machine-learning literature of engineering and 
computer science (Cui and Curry 2005). Machine learning is slowly making its way in marketing science (Abernethy, Evgeniou, Toubia and Vert 2008). In the context of the cinema market it has been used for recommender systems of movies. However, in these applications datasets were formed using aggregated publicly available databases (see Cheung, Kwok, Law and Tsui 2003).

Previous studies have proposed different measures of star power. Some of them are related with the consistency of stars' past box office success, that is the bankability of the stars. Alternatively, star power can also be approximated by star buzz measured by the intensity of internet searches about a given star (Karniouchina 2010). This paper analyzes whether superstar ability to persuade spectators is affected by the facet of superstar power considered (bankability/star buzz).

The rest of the paper is organized as follows. Section 2 discusses the major theoretical frameworks of persuasion, with particular emphasis on the theoretical approaches to explaining the underlying processes of persuasive communication. Section 3 describes the different alternative gauges of star power, the empirical study and the data mining process. Section 4 presents the main results and the last section gives some concluding remarks.

2. Theoretical background

The effect of persuasion variables changes with the circumstances (Petty, Priester and Wegener 1994). In the search for an explanation for this variability it has been posited that persuasion can be achieved by two different paths (O'Keefe 1990). While one path implies an elaborated and conscious information treatment, the other is associated with a more relaxed 
elaboration. In this context, elaboration can be understood as "the extent to which people think about issue-relevant arguments contained in persuasive messages" (Lien 2001). The Elaboration Likelihood Model -ELM- (Petty and Cacioppo 1986) and the Heuristic Systematic Model - HSM - (Chaiken, Liberman and Eagly 1989) are the most relevant contributions of this dual perspective.

In the ELM the two paths to persuasion are the central and the peripheral routes while in the HSM are the systematic and heuristic modes. Thus, persuasion can be the consequence of a high level cognitive processing of information or, on the contrary, it can be based on affective associations or on mere inferences. Therefore, when the elaboration likelihood is high there is a central/systematic route/mode whereas when it is low there is a peripheral/heuristic route/mode. This distinction is relevant since attitude changes promoted by the central route seem to be more persistent and to have more influence over behavior. Although there are differences between both models (Eagly and Chaiken 1993; Petty et al. 1994) they have at least three points in common (Kruglanski and Thompson 1999): they depict persuasion as attainable by two qualitative distinct paths; they consider that motivation and ability to process information favor the extensive elaboration of message arguments; and they both admit the possibility of co-occurrence between the two paths to persuasion.

In spite of the usefulness of the dual process approach to persuasion, the fact is that neither the central nor the peripheral approach can explain by itself the complex process of attitude change (Petty and Cacioppo 1986). A combination of message arguments and peripheral cues seems to guide individuals' responses (Lord, Lee and Sauer 1995). According to the ELM there is a continuum of elaboration likelihood whose extremes are the central and the peripheral route (ELM). Meanwhile, the HSM allows orthogonality in the use of both paths to persuasion. Taking into account this dual-process literature, the Unimodel (Kruglanski and Thompson 1999) proposes an integration of the two routes to persuasion. Thus, the Unimodel 
offers a single-route reconceptualization that collapses the two paths to persuasion into one. The ELM and the HSM can be considered special cases of that alternative framework.

Taking into account the previous considerations, stars' persuasion can be the result of spectators given careful and thoughtful consideration to the information they possess about the star. These circumstances would fit well into a central or systematic approach. On the other hand, peripheral or heuristic approaches would explain stars' persuasion as a process that can occur relatively independent of the information about the star. Instead, spectators would rely on attitudes or emotions towards the star.

The distinction between these two routes or modes of superstars' persuasion is relevant because determines the type of information that is more likely to influence spectators. For example, a spectator can decide to scrutinize relevant information about the cast before seeing a given movie. On the other hand, he/she cannot spend the effort required to think carefully about the cast of the film. Instead, he/she can decide to focus on peripheral cues. His/her behavior would be the result of an association of the type "I fancy this superstar $\rightarrow$ It is a great movie". Finally, and yet of considerable importance, central/systematic and peripheral/heuristic paths differ in their consequences. Spectators' responses are expected to manifest greater temporal persistence when are a consequence of superstars' persuasion exerted via the central/systematic route/mode. However, superstars' persuasion accomplished via the remaining peripheral/heuristic mode is expected to be less consistent. 
3. Research method

\subsection{Measures of star power}

Bankability and star buzz are two different perspectives of star power. The former focuses on the industry side, while the latter is based on the spectators. It represents the difference between the hierarchy of talent as an approach to the superstar phenomenon (Rosen 1981) and the hierarchy of popularity (Adler 2006). The most relevant measure of star power based on bankability is the Ulmer Scale (www.ulmerscale.com). Alternatively, STARmeter offers a superstar ranking based on user search intensity in the leader portal Internet Movie Data Base, IMDB ( www.imdb.com).

Table 1 summarizes the most powerful stars according to Ulmer's Scale 2010 and to STARmeter 2010. As can be seen, there are only three top stars both in bankability (Ulmer's Scale) and buzz (Starmeter): Brad Pitt, Johnny Depp and Leonardo Di Caprio.

\begin{tabular}{lcc}
\hline & ULMER SCALE & STARMETER \\
\hline Brad Pitt & 3 & 5 \\
Christian Bale & - & 7 \\
George Clooney & 5 & - \\
Gerald Butler & - & 8 \\
Johnny Depp & 2 & 1 \\
Kristen Stewart & - & 2 \\
Leonardo DiCaprio & 9 & 4 \\
Megan Fox & - & 9 \\
Nicholas Cage & 8 & - \\
Reese Witherspoon & 7 & - \\
Robert Downey & - & 6 \\
Robert Pattison & - & 3 \\
Russell Crowe & 10 & - \\
Tom Hanks & 4 & - \\
Will Ferrell & 6 & - \\
Will Smith & 1 & - \\
Zoe Saldana & - & 10 \\
\hline Table 1: 2010 Superstar & &
\end{tabular}

Table 1: 2010 Superstar ranking 
3.2 Sample and data collection

A personal survey was used to collect the data. Previous studies show that the main segment of cinema audience is young people with high levels of education (Collins et al. 2002), and this coincides with the profile of the cinema audience in the European country where the empirical study was carried out (Ministry of Culture 2011). Taking this into account, a sample of 320 respondents was randomly selected by a stratified sampling, using gender of respondent as the stratification variable. This allowed to have a balanced sample in terms of gender, the same as occurs in the population as a whole (AIMC 2011). The cinema attendance between the sample and the population was compared. No statistical differences were found between them $\left(\chi^{2}=10.11<\chi_{d . f=4, p=0.05}^{2 *}=11.14\right)$. Table 2 provides demographic details of the final sample.

\begin{tabular}{|c|c|}
\hline & Age \\
\hline Mean & 22.5 \\
\hline \multirow[t]{2}{*}{ s.d. } & 2.6 \\
\hline & Gender \\
\hline Male & $48.8 \%$ \\
\hline Female & $51.2 \%$ \\
\hline Total & $100 \%$ \\
\hline
\end{tabular}

Table 2: Sample profile

\subsection{Survey design}

The survey instrument consists of a total of 22 scale items used to measure the following variables: 
- Knowledge about the actors. It was measured by five-point-scale with four items adapted from Hoyer and Brown (1990).

- Attitude towards the stars. It was operationalized by means of a five-point scale with nine items developed by Christensen (2006).

- Emotional responses associated with stars. It was measured through the use of eight basic emotions of the hierarchical consumer emotions model (Laros and Steenkamp, 2005). The emotions were measured on a five- point scale.

Intention of watching a film. It was a one item scale. This alternative is very frequent in shopping behavior studies (Christensen 2006).

Table 3 provides summary statistics on the data.

Table 3: Knowledge, Attitude, Emotional response and Intention (Mean, Standard Deviation)

\begin{tabular}{lcccccccc}
\hline & \multicolumn{2}{c}{ Knowledge } & \multicolumn{2}{c}{ Attitude } & \multicolumn{2}{c}{$\begin{array}{c}\text { Emotional } \\
\text { response }\end{array}$} & Intention \\
\cline { 2 - 9 } Superstar & Mean & SD & Mean & SD & Mean & SD & Mean & SD \\
\hline Brad Pitt & 4.6 & 0.5 & 3.5 & 0.6 & 2.6 & 0.7 & 3.6 & 1.3 \\
\hline Christian Bale & 2.3 & 1.3 & 2.2 & 0.9 & 1.9 & 0.8 & 2.2 & 1.3 \\
\hline George Clooney & 4.3 & 0,8 & 3.3 & 0.6 & 2.5 & 0.7 & 3.2 & 1.2 \\
\hline Gerard Butler & 2.4 & 1.4 & 2.4 & 1.0 & 2.0 & 0.8 & 2.3 & 1.3 \\
\hline Johnny Depp & 4.3 & 0.8 & 3.3 & 0.6 & 2.6 & 0.8 & 3.7 & 1.3 \\
\hline Kristen Stewart & 2.4 & 1.4 & 2.2 & 0.8 & 2.0 & 0.8 & 1.8 & 1.1 \\
\hline Leonardo DiCap. & 4.4 & 0.6 & 3.2 & 0.6 & 2.5 & 0.7 & 3.1 & 1.4 \\
\hline Megan Fox & 3.7 & 1.0 & 3.1 & 0.8 & 2.3 & 0.8 & 2.7 & 1.5 \\
\hline Nicholas Cage & 4.1 & 0.8 & 3.0 & 0.6 & 2.3 & 0.8 & 3.1 & 1.4 \\
\hline & & & & & & & & \\
\hline
\end{tabular}




\begin{tabular}{lcccccccc}
\hline Reese Wither. & 2.5 & 1.4 & 2.4 & 1.0 & 2.1 & 0.9 & 2.0 & 1.3 \\
\hline Robert Downey Jr. & 2.3 & 1.3 & 2.3 & 0.9 & 1.9 & 0.8 & 2.1 & 1.2 \\
\hline Robert Pattison & 3.3 & 1.3 & 2.7 & 0.8 & 2.3 & 0.8 & 2.2 & 1.3 \\
\hline Russell Crowe & 3.5 & 1.2 & 2.9 & 0.8 & 2.3 & 0.8 & 3.0 & 1.4 \\
\hline Tom Hanks & 4.0 & 0.9 & 3.1 & 0.7 & 2.4 & 0.8 & 3.2 & 1.4 \\
\hline Will Ferrell & 1.8 & 1.1 & 2.1 & 0.9 & 1.9 & 0.9 & 1.8 & 1.1 \\
\hline Will Smith & 4.4 & 0.7 & 3.5 & 0.7 & 2.7 & 0.8 & 4.0 & 1.2 \\
\hline Zoe Saldana & 1.6 & 1.0 & 2.0 & 0.9 & 1.7 & 0.8 & 1.6 & 1.0 \\
\hline
\end{tabular}

\subsection{Data mining process}

The stars' persuasion capacity can be the result of what is known about the actor (central/systematic route/mode) and/or a consequence of the attitude towards the stars or emotional responses associated with the stars (peripheral/heuristic route/mode). The knowledge, attitudes and emotions can be considered inputs of machine learning techniques, whereas the intention to see a movie is the output variable. The superiority of machine learning techniques over other empirical approaches, i.e. logistical regression, resides in the fact that machine learning techniques do not require a priori assumptions about how the relationship between the explicative variables related with the different routes of persuasion and the dependent variable is. Additionally, the values of the output variable (intention of watching a film) have an ordered relationship what provides useful information that can potentially improve the predictive performance of the methods (Hühn and Hüllermeier 2009). Among the specific approaches in the literature to cope with this kind of problem, support 
vector ordinal regression (SVOR) is the most promising (Chu and Keerthi 2007). This method optimizes multiple thresholds in order to define parallel discriminant hyperplanes for the ordinal scales and it guarantees that the thresholds are properly ordered at the optimal solution. Another advantage with regard to other state-of-the-art approaches is that the size of these optimization problems is linear in the number of training samples. Moreover, the optimization algorithm is easy to implement and it scales efficiently as a quadratic function of the number of examples.

Several models using the SVOR approach were built. The different models were obtained taking the variables related to the central/systematic route/mode (knowledge), the variables related with the peripheral/heuristic route/mode (attitude-emotion); the attitude towards the stars (peripheral/heuristic route/mode), the emotions towards the stars (peripheral/heuristic route/mode) and the combinations knowledge-attitude and knowledge-emotion. According to this technique, the better the performance the models reach, the better the group of variables considered explains the intention of watching a movie.

\section{Results}

A recurrent demand in recent studies of the cinema market is the need to take into account different socio-demographic features of the spectators in order to explain discrepancies in behavior (Redondo and Holbrook 2010). For this reason, differences in the results between spectators' gender are presented.

The SVOR applied is that described in Chu and Keerthi (2007) with linear kernel. A 5fold cross-validation was repeated twice. To adjust the regularization parameter $\mathrm{C}$ an internal 
grid search was performed (a 2-fold cross-validation repeated three times) with $\mathrm{C}=10^{\mathrm{p}}$ and $\mathrm{p}^{\in}[-2,2]$.

The estimation output consists in the mean absolute error of the different models. The output of a fully SVOR can be difficult to interpret. Tables A.1 to A.6 in de Appendix show the mean absolute error of the different SVOR models for the top stars both in bankability and buzz (Tables A.1 and A.2 in the Appendix), the top stars in bankability (Tables A.3 and A.4 in the Appendix) and the top stars in buzz (Tables A.5 and A.6 in the Appendix), for both men and women. In these tables the numbers in parentheses indicates the resulting ranks. As eight different models are compared, the rank 1 corresponds to the model with minimum error and the rank 8 to the one with the maximum error. In the case of ties, average ranks are computed. Graphical display of this output can be instructive. Figures 1 to 3 below show the average ranks of the different models for the different types of superstars.
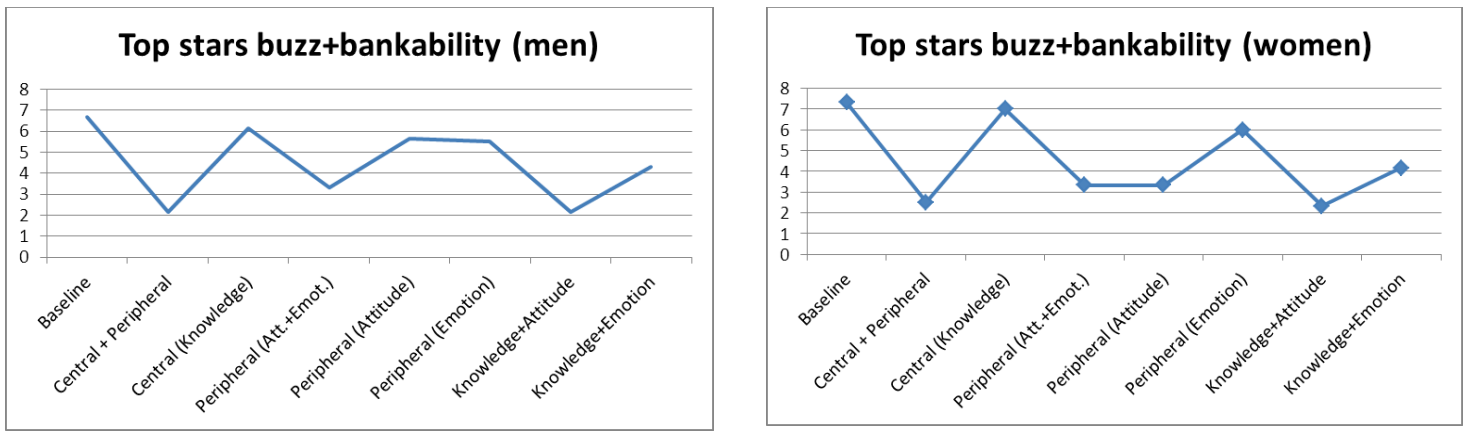

Figure 1: Average ranks for top stars both in buzz and bankability corresponding to SVOR models 

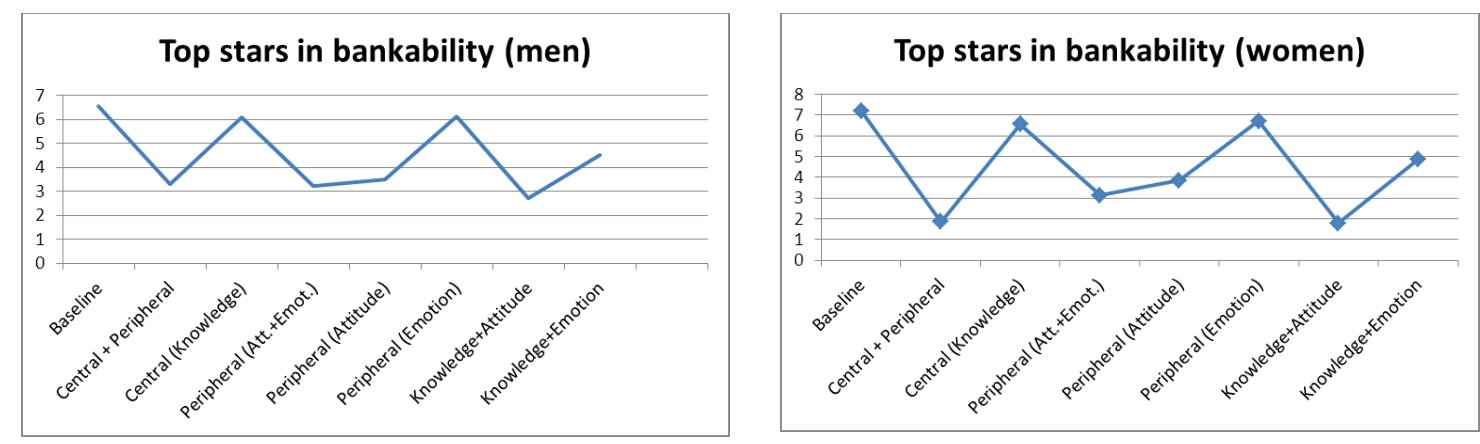

Figure 2: Average ranks for top stars in bankability corresponding to SVOR models
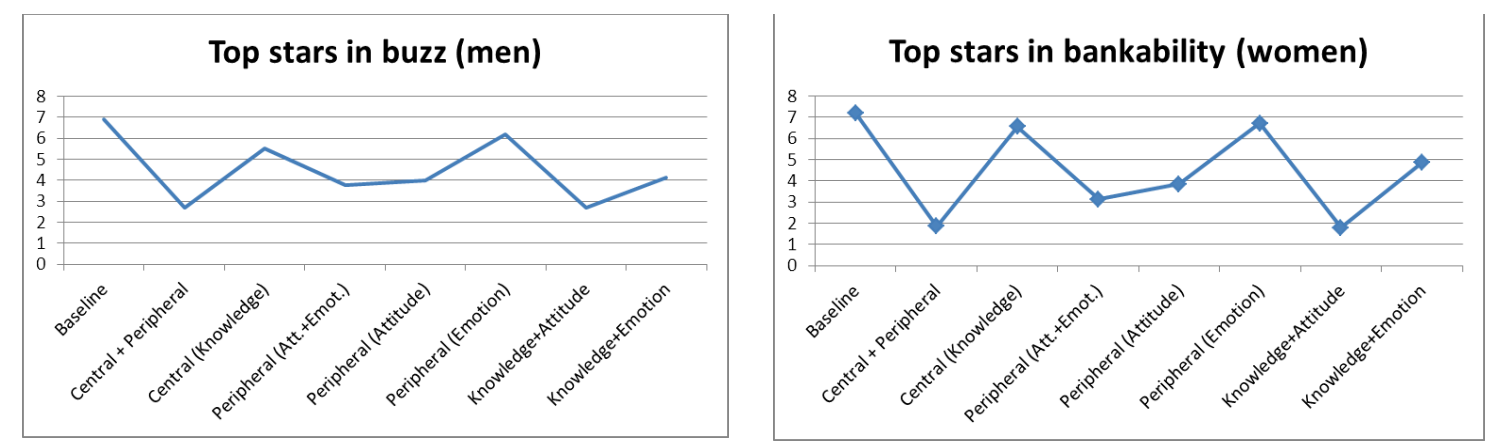

Figure 3: Average ranks for top stars in buzz corresponding to SVOR models

Figures 1 to 3 show the average classification accuracies across the tested models. Average ranks by themselves provide a fair comparison of the models. Furthermore, these averaging error rates can be compared in statistical terms. Following Demsar's recommendations (Demsar 2006), the Iman and Daverport test (1980) is used. It is a robust non-parametric test for statistical comparison of different models. This statistic is based on the Friedman test (Friedman, 1937, 1940) and it is estimated as:

$$
F_{F}=\frac{(N-1) X_{F}^{2}}{N(k-1)-X_{F}^{2}}
$$

where, 
$X_{F}^{2}=\frac{12 N}{k(k+1)}\left[\sum_{j} R_{j}^{2}-\frac{k(k+1)^{2}}{4}\right]$

$R_{j}=\frac{1}{N} \sum_{i} r_{i}^{j}$, is the average ranks of models. $r_{i}^{j}$ is the rank of the $\mathrm{j}$-th of $\mathrm{k}=8$ models on the $\mathrm{i}$-th of $\mathrm{N}$ data sets $(\mathrm{N}=3$ in the case of top stars in bankability and buzz; $\mathrm{N}=7$ in the other two cases, see Table 1). The null-hypothesis of this test states that all the models are equivalent and so their ranks $\mathrm{R}_{\mathrm{j}}$ should be equal.

The $\mathrm{F}_{\mathrm{F}}$ is distributed according to the F-distribution with k-1 and $(\mathrm{k}-1)(\mathrm{N}-1)$ degrees of freedom. Table 4 shows the results of the tests.

\begin{tabular}{l|lccc}
\hline Gender & \multicolumn{1}{|c}{$\begin{array}{c}\text { Type of stars } \\
\text { (test }\end{array}$} & $\begin{array}{c}\text { Friedman } \\
\text { test }\end{array}$ & $\begin{array}{c}\text { Iman and Davenport } \\
\text { test }\end{array}$ & $\begin{array}{c}\text { Critical } \\
\text { values } \\
\text { (CL=95 } \\
\%)\end{array}$ \\
\hline \multirow{3}{*}{ Men } & Top stars (bankability and buzz) & 11.05 & & 2.76 \\
& Top stars (bankability) & 19.57 & 3.22 & 2.24 \\
& Top stars (buzz) & 19.95 & 4.12 & 2.24 \\
& Top stars (bankability and buzz) & 14.02 & 4.02 & 2.76 \\
& Top stars (bankability) & 38.84 & 22.95 & 2.24 \\
& Top stars (buzz) & 29.52 & 9.09 & 2.24 \\
\hline
\end{tabular}

Table 4: Comparison of SVOR models

The null-hypothesis of equivalence of the different models is rejected both for men and women except in the case of the men and for top stars in bankability and buzz $(2.22<2.76)$. In the other cases, post-hoc tests are carried out for comparing the models. A Bonferroni-Dunn test (Dunn 1961) allows a pairwise comparison with the baseline approach (Table 5). The baseline approach does not take into account any of the input variables. In fact, it consists in always predicting the median of the values of the output variable. To perform the BonferroniDunn test it is possible to compare the corresponding average ranks of two models using the critical difference calculated as (Nemenyi 1963): 
$C D=q_{\propto} \sqrt{\frac{k(k+1)}{6 N}}$

where $\mathrm{q}_{\alpha}$ are the critical values based on the Studentized range statistic divided by $\sqrt{2}$. The Bonferroni-Dunn test uses the critical values for $\frac{\alpha}{(k-1)}$.

\begin{tabular}{|c|c|c|c|c|c|c|c|c|c|}
\hline & Models* & $\mathrm{C}+\mathrm{P}$ & $\mathrm{C}$ & $\mathrm{P}$ & $\mathrm{P}$ & $\mathrm{P}$ & Comb. & Comb. & \\
\hline Gender & Type of stars & All & Know. & $\begin{array}{l}\text { Att- } \\
\text { Emo }\end{array}$ & Att. & Emot. & $\begin{array}{l}\text { Know- } \\
\text { Att }\end{array}$ & $\begin{array}{l}\text { Know- } \\
\text { Em }\end{array}$ & $\begin{array}{l}\text { Critical } \\
\text { values } \\
(95 \%) \\
\end{array}$ \\
\hline \multirow[t]{3}{*}{ Men } & $\begin{array}{l}\text { Top stars (bankability } \\
\text { and buzz) }\end{array}$ & 1 & 0 & 1 & 0,33 & 0,66 & 1 & 0.33 & 1.13 \\
\hline & Top stars (bankability) & 0.71 & 0.14 & 0.71 & $0.85 * *$ & 0.14 & $0.85^{* *}$ & 0.71 & 0.74 \\
\hline & Top stars (buzz) & 0.71 & 0.57 & $1 * *$ & $1 * *$ & 0.28 & $0.85^{* *}$ & 0.42 & 0.74 \\
\hline \multirow[t]{3}{*}{ Women } & $\begin{array}{l}\text { Top stars (bankability } \\
\text { and buzz) }\end{array}$ & 1 & 0.33 & 1 & 0.33 & 1 & 1 & 1 & 1.13 \\
\hline & Top stars (bankability) & $1 * *$ & 0.14 & $1 * *$ & $1 * *$ & 0.28 & $1 * *$ & $1 * *$ & 0.74 \\
\hline & Top stars (buzz) & $1 * *$ & 0.42 & $0.85^{*}$ & 0.71 & $1 * *$ & $0.85 * *$ & $1 * *$ & 0.74 \\
\hline
\end{tabular}

${ }^{*} \mathrm{C}=\mathrm{Central} /$ systematic route/mode; $\mathrm{P}=$ Peripheral/heuristic route/mode; $\mathrm{Comb} .=$ Combination **Significative differences

Table 5: Difference between average ranks-Bonferroni-Dunn test (95\%)

Table 5 presents the results of the Bonferroni-Dunn test. Some differences between men and women can be noted. In the case of men, and for top stars in bankability, the intention of watching a film is explained by attitude towards the actors, either alone or in combination with the knowledge about the actors. However, knowledge by itself is not a relevant predictor of intention. In the case of top stars in buzz the same results can be sustained but there is also a significant difference between the variables attitude-emotion and the baseline. These differences do not exist in the case of emotion by itself. 
In the case of women, and for top stars in bankability, all the variables together are relevant in comparison with the baseline model. If the effect of each variable is isolated, it can be seen that knowledge is significant only in combination with attitude or emotion, but not by itself. There are significant differences between a model based on attitude and the baseline model. This influence of attitude is relevant by itself or in combination with the other two possible variables (Knowledge-Attitude; Attitude-Emotion). So for women emotions towards stars in bankability play an important role when combined with knowledge and attitude but not by themselves. In the case of top stars in buzz, knowledge does not have a significant difference except if it is combined with attitude or emotion. There are no significant differences between attitude and the baseline. These differences only appear when attitude is combined with knowledge or emotion. However, it is remarkable that for this public and this kind of stars emotion is relevant in any case, alone or combined with knowledge or attitude. These results provide support for the idea that message-relevant emotions influence information processing (Kühne and Schemer 2013).

\section{Conclusions and future work}

The results of this paper confirm that the difference between top stars in bankability and top stars in buzz is relevant. In particular, the study demonstrates that they are related to different paths to persuasion over spectators.

The study shows that stars' persuasion is related to the spectators' gender. Moreover, the influence of stars is mainly the consequence of a peripheral/heuristic route/mode to 
persuasion in men and women. The study indicates that the influence of knowledge must be accompanied by attitudes towards the stars and emotions associated with them. This emotional dimension is more influential over women than in the case of men. Furthermore, the intention of watching a film with top stars in bankability is related with attitude and with the binomial knowledge-attitude. The same occurs when the stars in buzz are considered but, in this case, the binomial attitude-emotion is also relevant. So, for men it appears possible that the hook effect of the industry's top stars depends on knowledge and attitude. However, the attitude is also tempered by emotion for top stars for the market (top stars in buzz). For women the intention of watching a film is influenced not only by knowledge-attitude but also by knowledge-emotion. This relationship occurs for top stars in bankability and for top stars in buzz. It might thus be argued that for women there is a more pronounced balance between the central/systematic route/mode of star persuasion and the peripheral/heuristic one. Apart from that, when top stars in buzz are involved, women are less influenced by attitude and more influenced by emotion than men. This fact suggests that women's emotions through stars may trigger the intention of watching a film in the case of the stars that are considered top by the market (top stars in buzz).

Of special significance, the implications of these results are more important if the difference between intention and behavior is taken into account. Overall, the results indicate that the intention to see a certain film is more influenced by a peripheral/heuristic route/mode. The ELM predicts a weaker link between intention and behavior when this intention is a result of a peripheral/heuristic rather than a central/systematic route/mode to persuasion. As evidenced by this research, in the cinema market, this trend is more pronounced for men and for top stars in bankability. In this case the lowest level of behavior change in response to the presence of stars can be predicted. 
These results pinpoint a difference between brand persuasion and star persuasion. Brand knowledge makes consumers comfortable with brands. However, knowledge of the cast is not enough to affect the intention of watching a film, even in the case of superstars. One possible explanation is that market knowledge about a star does not necessarily mean a better evaluation of the star. This reason explains why knowledge only affects intention when accompanied by emotion and/or attitude.

Another interesting result is that top stars both in bankability and buzz deserve special attention. Machine learning allows adopting different patterns of spectator thinking. None of the patterns analyzed in this study serve to explain the persuasion of this kind of stars. This result is particularly noteworthy taking into account that some of the variables considered are relevant for the other two kinds of superstars. In the case of men, there was no relevant difference between the models considered for top stars both in bankability and buzz. In the case of women, there was a difference but none of the models could explain more than the baseline. This result merits future investigation. Top stars both in bankability and buzz are particularly interesting because they are superstars independent of the facet of stardom considered. They are stars according to a hierarchy of talent and a hierarchy of popularity.

This study has some limitations that may be taken into account. First of all, it analyzes only the young segment. It is the most important segment of the cinema demand. In fact, motion picture companies encourage the importance of this segment. The reason behind this importance is that young people have very similar attitudes and behavior around the world. It is the most global segment and can be used as the main target of most super productions because it guarantees worldwide success (e.g. The Hunger Games or Divergent). Furthermore, it is very probable that the majority of the searches that classify a star according to buzz come from young people. But, even in spite of these circumstances, it could be very 
interesting to compare the influence of the different paths to persuasion between spectators of different ages.

This paper focuses on the effect of a single star in the intention of watching a film. This approach does not take into account the possible synergy derived from the presence of multiple stars (Nelson and Glotfelty 2012). Apart from that, the intention of watching a film has been related only with stars. It is obvious that this intention can be affected by many other variables, the genre or the plot, for example. Star power as a concept tries to isolate the unique influence of the star by himself/herself. It could be discussed if star power is really a power of the stars or if it can only be displayed along with the other components of the film package. Research about this topic could make interesting and valuable contributions. 
References

Abernethy J., Evgeniou T., Toubia O. \& Vert JP (2008). Eliciting consumer preferences using robust adaptive choice questionnaires. IEEE Transactions on knowledge and data engineering, 20 (2), 145-155. doi: 10.1109/TKDE.2007.1031

Adler M. (2006). Stardom and talent. In V. A. Ginsburgh \& D. Throsby (Eds.), Handbook of the economics of art and culture 1 (pp. 895-906). North-Holland: Elsevier.

AIMC (2011). Study of communication media. Available at http:// www.aimc.es [Accessed on September 2013].

Cacioppo J.T., Petty R.E. \& Berntson G.G. (1991). Persuasion. Encyclopedia of human biology, 5, 799-810.

Collins A. \&, Hand C. (2005). Analyzing moviegoing demand: an individual-level crosssectional approach. Managerial and Decision Economics, 26, 319-330. doi: $10.1002 /$ mde. 1231

Cui D. \& Curry D. (2005). Prediction in marketing using the support vector machine. Marketing Science, 24 (4), 596-615. doi: 10.1287/mksc.1050.0123

Chaiken S., Liberman A. \& Eagly A.H. (1989). Heuristic and systematic processing within and beyond the persuasion context. In J.S. Uleman \& J.A. Bargh (Eds.), Unintended thought (pp. 212-252). New York, NY: Guilford.

Cheung K.W., Kwok J.T., Law M.H. \& Tsui K.Ch. (2003). Mining customer product ratings for personalized marketing. Decision Support Systems, 35, 231-243. 
Christensen S.R. (2006). Measuring consumer reactions to sponsoring partnerships based upon emotional and attitudinal responses. International Journal of Market Research, 48, 6180.

Chu W. \& Keerthi S.S. (2007). Support vector ordinal regression. Neural Computation, 19 (3), 792-815. doi: 10.1162/neco.2007.19.3.792

Demsar J. (2006). Statistical comparisons of classifiers over multiple data sets. Journal of Machine Learning Research, 7, 1-30.

Dunn O.J. (1961). Multiple comparisons among means. Journal of the American Statistical Association, 56, 52-64. doi: 10.1080/01621459.1961.10482090

Eagly A.H. \& Chaiken S. (1993). The psychology of attitudes. Fort Worth, TX: Harcourt Brace Jovanovich.

Eliashberg, J., Elberse, A., \& Leenders, M. A. (2006). The motion picture industry: critical issues in practice, current research, and new research directions. Marketing Science, 25 (6), $638-661$.

Friedman M. (1937). The use of ranks to avoid the assumption of normality implicit in the analysis of variance. Journal of the American Statistical Association, 32, 675-701. doi: $10.1080 / 01621459.1937 .10503522$

Friedman M. (1940). A comparison of alternative tests of significance for the problem of $m$ rankings. Annals of the Mathematical Statistics, 11, 86-92.

Hoyer W.D. \& Brown S.P. (1990). Effects of Brand Awareness on Choice for a Common, Repeat-Purchase Product. Journal of Consumer Research, 17, 141-148. 
Hühn J.Ch. \& Hüllermeier E. (2009). FR3: A Fuzzy Rule Learner for Inducing Reliable Classifiers. IEEE Transactions on Fuzzy Systems, 17, 138-149. doi: 10.1109/TFUZZ.2008.2005490

Kühne R. \& Schemer C. (2013). The emotional effects of new frames on information processing and opinion formation. Communication Research. Prepublished December, 9, doi: $10.1177 / 0093650213514599$

Iman R.L. \& Davenport J.M. (1980). Approximations of the critical region of the Friedman statistic. Communications in Statistics 9: 571-595. doi: 10.1080/03610928008827904

Karniouchina E.V. (2010). Impact of star and movie buzz on motion picture distribution and box office revenue. International Journal of Research in Marketing, 8 (1), 62-74.

Kruglanski A.W. \& Thompson E.P. (1999). Persuasion by a single route: a view from the unimodel. Psychological Inquiry, 10 (2), 83-109. doi: 10.1207/S15327965PL100201

Laros F.J.M. \& Steenkamp J.E.M. (2005). Emotions in consumer behaviour: a hierarchical approach. Journal of Business Research, 58, 1437-1445. doi: :10.1016/j.jbusres.2003.09.013

Lien N.H. (2001). Elaboration likelihood model in consumer research: a review. Proceeding of the National Science Council, 11 (4): 301-310.

Lord K.R., Lee M. \& Sauer P.L. (1995). The combined influence hypothesis: Central and peripheral antecedents of attitude toward the ad. Journal of Advertising, 24, 73-85. doi: $10.1080 / 00913367.1995 .10673469$

Ministry of Culture (2011). Encuesta de hábitos y prácticas culturales en España 2010-11. Available at http://www.mcu.es/estadisticas/MC/EHC/2010/Presentacion.html [Accessed on November 2013]. 
Nelson R.A. \& Glotfelty R. (2012). Movie stars and box office revenues: an empirical analysis. Journal of Cultural Economics, 36 (2), 141-166. doi: 10.1007/s10824-012-9159-5

Nemenyi P.B. (1963). Distribution-free multiple comparisons (Doctoral dissertation). Princeton University, Princeton, New Jersey.

O’Keefe D.J. (1990). Persuasion: theory and research. Newbury Park, CA: Sage.0

Petty R. \& Cacioppo J. (1986). Communication and persuasion: The central and the peripherals routes to attitude change. New York, NY: Springer Verlag.

Petty R.E., Priester J.R. \& Wegener D.T. (1994). Cognitive processes in attitude change. In R.S. Wyer, Jr. \& T.K. Srull (Eds.), Handbook of social cognition 2 (pp. 69-142). Hillsdale, NJ: Lawrence Erlbaum.

Ravid, S. A. (1999). Information, blockbusters, and stars: a study of the film industry. The Journal of Business, 72 (4), 463-492.

Redondo I. \& Holbrook M.B. (2010). Modelling the appeal of movie features to demographic segments of theatrical demand. Journal of Cultural Economics, 34 (4), 299-315. doi: 10.1007/s10824-010-9127-x

Richins M.L. (1997). Measuring emotions in the consumption experience. Journal of Consumer Research, 24 (2), 127 - 146. doi: 10.1086/209499

Rosen S. (1981). The economics of superstars. The American Economic Review, 71 (5), 845858.

Walls W.D. (2009). Screen wars, star wars, and sequels: nonparametric reanalysis of movie profitability. Empirical economics, 37 (2), 447-461. 
Appendix

\begin{tabular}{l|cccccccc}
\hline \multicolumn{1}{c|}{ Models* } & & $\mathrm{C}+\mathrm{P}$ & $\mathrm{C}$ & $\mathrm{P}$ & $\mathrm{P}$ & $\mathrm{P}$ & Combination & Combination \\
\hline Stars & Baseline & All & Knowledge & Att-Emo & Attitude & Emotion & Know-Att & Know-Em \\
\hline Pitt & $1.24(7.5)$ & $1.08(2.5)$ & $1.24(7.5)$ & $1.07(1)$ & $1.13(6)$ & $1.12(5)$ & $1.08(2.5)$ & $1.11(4)$ \\
Depp & $1.02(7)$ & $0.93(2)$ & $0.97(4)$ & $0.98(5)$ & $1.03(8)$ & $1.01(6)$ & $0.96(3)$ & $0.89(1)$ \\
DiCaprio & $1.23(5.5)$ & $1.16(2)$ & $1.25(7)$ & $1.22(4)$ & $1.18(3)$ & $1.23(5.5)$ & $1.14(1)$ & $1.26(8)$ \\
\hline $\begin{array}{l}\text { Average } \\
\text { rank }\end{array}$ & 6.67 & 2.17 & 6.17 & 3.33 & 5.67 & 5.50 & 2.17 & 4.33 \\
\multicolumn{7}{l}{$* \mathrm{C}=$ Central/systematic route/mode; $\mathrm{P}=$ Peripheral/heuristic route/mode }
\end{tabular}

Table A.1: Mean absolute errors for SVOR models for top stars both in bankability and buzz (men)

\begin{tabular}{|c|c|c|c|c|c|c|c|c|}
\hline Models* & & $\mathrm{C}+\mathrm{P}$ & C & $\mathrm{P}$ & $\mathrm{P}$ & $\mathrm{P}$ & Combination & Combination \\
\hline Stars & Baseline & All & Knowledge & Att-Emo & Attitude & Emotion & Know-Att & Know-Em \\
\hline Pitt & $0.99(6)$ & $0.95(2)$ & $1.02(8)$ & $0.94(1)$ & $1.01(7)$ & $0.98(5)$ & $0.96(3.5)$ & $0.96(3.5)$ \\
\hline Depp & $1.03(8)$ & $0.78(3)$ & $0.91(6)$ & $0.83(5)$ & $0.77(2)$ & $1.02(7)$ & $0.76(1)$ & $0.82(4)$ \\
\hline DiCaprio & $1.18(8)$ & $0.84(2.5)$ & $1.17(7)$ & $0.86(4)$ & $0.82(1)$ & $1.11(6)$ & $0.84(2.5)$ & $1.02(5)$ \\
\hline Average rank & 7.33 & 2.50 & 7.00 & 3.33 & 3.33 & 6.00 & 2.33 & 4.17 \\
\hline
\end{tabular}

${ }^{*} \mathrm{C}=$ Central/systematic route/mode; $\mathrm{P}=$ Peripheral/heuristic route/mode

Table A.2: Mean absolute errors for SVOR models top stars both in bankability and buzz (women)

\begin{tabular}{l|llllllll}
\hline \multicolumn{1}{c}{ Models* } & \multicolumn{3}{c}{$\mathrm{C}+\mathrm{P}$} & $\mathrm{C}$ & $\mathrm{P}$ & $\mathrm{P}$ & $\mathrm{P}$ & \multicolumn{2}{c}{ Combination } & Combination \\
\hline Stars & Baseline & All & Knowledge & Att-Emo & Attitude & Emotion & Know-Att & Know-Em \\
\hline Clooney & $1.01(2.5)$ & $1.04(7.5)$ & $1.01(2.5)$ & $1.04(7.5)$ & $1.01(2.5)$ & $1.03(5.5)$ & $1.01(2.5)$ & $1.03(5.5)$ \\
Cage & $1.12(7.5)$ & $1.03(2.5)$ & $1.12(7.5)$ & $0.97(1)$ & $1.03(2.5)$ & $1.09(5)$ & $1.05(4)$ & $1.11(6)$ \\
Witherspoon & $1.01(7)$ & $0.76(3.5)$ & $1.03(8)$ & $0.76(3.5)$ & $0.72(1)$ & $0.97(6)$ & $0.75(2)$ & $0.95(5)$ \\
Crowe & $1.23(7)$ & $1.00(2)$ & $1.05(4)$ & $1.07(5)$ & $1.10(6)$ & $1.24(8)$ & $1.00(2)$ & $1.00(2)$ \\
Hanks & $1.21(8)$ & $1.06(2)$ & $1.19(6)$ & $1.03(1)$ & $1.08(4)$ & $1.18(5)$ & $1.07(3)$ & $1.20(7)$ \\
Ferrell & $0.92(6)$ & $0.86(2)$ & $0.94(8)$ & $0.88(3.5)$ & $0.91(5)$ & $0.93(7)$ & $0.88(3.5)$ & $0.81(1)$ \\
Smith & $0.87(8)$ & $0.70(3.5)$ & $0.83(6.5)$ & $0.65(1)$ & $0.70(3.5)$ & $0.83(6.5)$ & $0.69(2)$ & $0.78(5)$ \\
\hline $\begin{array}{l}\text { Average } \\
\text { rank }\end{array}$ & 6.57 & 3.29 & 6.07 & 3.21 & 3.50 & 6.14 & 2.71 & 4.50 \\
\hline *C Central/systematic route/mode; P=Peripheral/heuristic route/mode & & & &
\end{tabular}

Table A.3: Mean absolute errors for SVOR models for top stars in bankability (men) 


\begin{tabular}{l|cccccccc}
\hline \multicolumn{1}{c}{ Models* } & & $\mathrm{C}+\mathrm{P}$ & $\mathrm{C}$ & $\mathrm{P}$ & $\mathrm{P}$ & $\mathrm{P}$ & Combination & Combination \\
\hline Stars & Baseline & All & Knowledge & Att-Emo & Attitude & Emotion & Know-Att & Know-Em \\
\hline Clooney & $1.07(7.5)$ & $0.94(3)$ & $1.07(7.5)$ & $0.93(2)$ & $0.97(4)$ & $1.03(6)$ & $0.88(1)$ & $0.99(5)$ \\
Cage & $1.23(8)$ & $0.99(1)$ & $1.21(7)$ & $1.10(3)$ & $1.15(5)$ & $1.17(6)$ & $1.08(2)$ & $1.11(4)$ \\
Wither. & $1.07(8)$ & $0.75(1)$ & $0.84(5.5)$ & $0.79(2.5)$ & $0.84(5.5)$ & $0.89(7)$ & $0.79(2.5)$ & $0.81(4)$ \\
Crowe & $1.22(6.5)$ & $1.04(4)$ & $1.25(8)$ & $1.03(2.5)$ & $1.03(2.5)$ & $1.22(6.5)$ & $1.02(1)$ & $1.17(5)$ \\
Hanks & $1.21(7.5)$ & $1.04(2)$ & $1.07(3)$ & $1.11(5)$ & $1.10(4)$ & $1.21(7.5)$ & $1.01(1)$ & $1.12(6)$ \\
Ferrell & $0.73(6)$ & $0.56(1)$ & $0.77(8)$ & $0.59(3)$ & $0.60(4)$ & $0.74(7)$ & $0.58(2)$ & $0.62(5)$ \\
Smith & $1.00(7)$ & $0.74(1)$ & $1.00(7)$ & $0.79(4)$ & $0.76(2)$ & $1.00(7)$ & $0.78(3)$ & $0.88(5)$ \\
\hline Average rank & 7.21 & 1.86 & 6.57 & 3.14 & 3.86 & 6.71 & 1.79 & 4.86 \\
\hline
\end{tabular}

${ }^{*} \mathrm{C}=\mathrm{Central} /$ systematic route/mode $; \mathrm{P}=$ Peripheral/heuristic route/mode

Table A.4: Mean absolute errors for SVOR models top stars in bankability (women)

\begin{tabular}{l|cccccccc}
\hline \multicolumn{1}{c|}{ Models* } & & $\mathrm{C}+\mathrm{P}$ & $\mathrm{C}$ & $\mathrm{P}$ & $\mathrm{P}$ & $\mathrm{P}$ & Combination & Combination \\
\hline Stars & Baseline & All & Knowledge & Att-Emo & Attitude & Emotion & Know-Att & Know-Em \\
\hline Bale & $1.18(7)$ & $0.83(2)$ & $0.84(3)$ & $0.94(6)$ & $0.88(5)$ & $1.20(8)$ & $0.82(1)$ & $0.85(4)$ \\
Butler & $1.21(8)$ & $0.72(1)$ & $0.79(4)$ & $0.83(6)$ & $0.81(5)$ & $0.88(7)$ & $0.76(2)$ & $0.77(3)$ \\
Stewart & $0.88(5.5)$ & $0.80(4)$ & $0.93(8)$ & $0.79(2.5)$ & $0.77(1)$ & $0.88(5.5)$ & $0.79(2.5)$ & $0.90(7)$ \\
Fox & $1.37(8)$ & $0.97(1)$ & $1.35(7)$ & $0.98(2)$ & $1.14(6)$ & $1.08(4)$ & $1.09(5)$ & $1.02(3)$ \\
Downey & $1.10(8)$ & $0.82(1)$ & $0.90(6)$ & $0.88(5)$ & $0.87(4)$ & $1.09(7)$ & $0.86(3)$ & $0.83(2)$ \\
Pattison & $0.88(4.5)$ & $0.89(7.5)$ & $0.88(4.5)$ & $0.86(1)$ & $0.87(2)$ & $0.88(4.5)$ & $0.88(4.5)$ & $0.89(7.5)$ \\
Saldana & $0.82(7.5)$ & $0.68(2.5)$ & $0.77(6)$ & $0.69(4)$ & $0.70(5)$ & $0.82(7.5)$ & $0.67(1)$ & $0.68(2.5)$ \\
\hline Average & 6.93 & 2.71 & 5.50 & 3.79 & 4.00 & 6.21 & 2.71 & 4.14 \\
rank & & & & & & & & \\
\hline
\end{tabular}

${ }^{*} \mathrm{C}=$ Central/systematic route/mode; $\mathrm{P}=$ Peripheral $/$ heuristic route $/$ mode

Table A.5: Mean absolute errors for SVOR models for top stars in buzz (men)

\begin{tabular}{l|cccccccc}
\hline \multicolumn{1}{c|}{ Models* } & & $\mathrm{C}+\mathrm{P}$ & $\mathrm{C}$ & $\mathrm{P}$ & $\mathrm{P}$ & $\mathrm{P}$ & Combination & Combination \\
\hline Stars & Baseline & All & Knowledge & Att-Emo & Attitude & Emotion & Know-Att & Know-Em \\
\hline Bale & $1.03(8)$ & $0.81(2)$ & $0.83(3.5)$ & $0.86(5)$ & $0.88(6)$ & $0.98(7)$ & $0.80(1)$ & $0.83(3.5)$ \\
Butler & $1.11(8)$ & $0.67(1)$ & $0.75(5.5)$ & $0.71(2.5)$ & $0.75(5.5)$ & $0.89(7)$ & $0.72(4)$ & $0.71(2.5)$ \\
Stewart & $0.85(7)$ & $0.67(3)$ & $0.86(8)$ & $0.65(1)$ & $0.66(2)$ & $0.79(6)$ & $0.70(4)$ & $0.74(5)$ \\
Fox & $1.16(8)$ & $0.81(1)$ & $1.09(7)$ & $0.83(2)$ & $0.88(4)$ & $0.92(6)$ & $0.87(3)$ & $0.89(5)$ \\
Downey & $0.95(8)$ & $0.71(2)$ & $0.83(7)$ & $0.70(1)$ & $0.73(4)$ & $0.79(6)$ & $0.72(3)$ & $0.77(5)$ \\
Pattison & $1.18(8)$ & $0.89(2)$ & $1.04(7)$ & $0.90(3.5)$ & $0.88(1)$ & $0.97(6)$ & $0.90(3.5)$ & $0.95(5)$ \\
Saldana & $0.52(5)$ & $0.48(2.5)$ & $0.53(7.5)$ & $0.52(5)$ & $0.53(7.5)$ & $0.48(2.5)$ & $0.52(5)$ & $0.42(1)$ \\
\hline $\begin{array}{l}\text { Average } \\
\text { rank }\end{array}$ & 7.43 & 1.93 & 6.50 & 2.86 & 4.29 & 5.79 & 3.36 & 3.86 \\
\hline \multirow{2}{*}{ C = Central/systematic } & & & & & & \\
\hline
\end{tabular}

${ }^{*} \mathrm{C}=$ Central/systematic route/mode; $\mathrm{P}=$ Peripheral/heuristic route/mode

Table A.6: Mean absolute errors for SVOR models for top stars in buzz (women) 